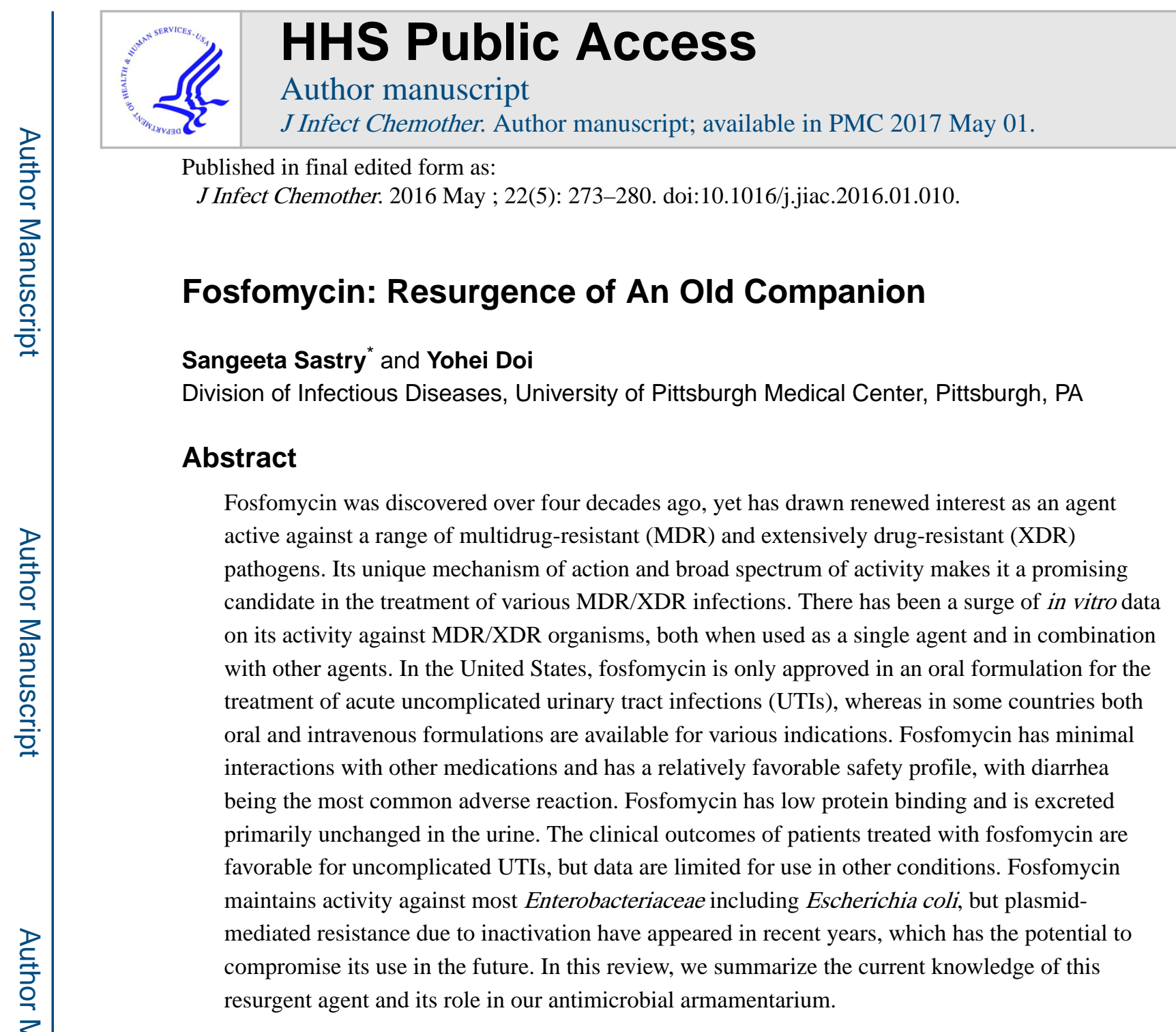

\title{
Keywords
}

phosphonic acid; multidrug resistance (MDR); extensive drug resistance (XDR); susceptibility testing; plasmid-mediated resistance; pharmacokinetics; combination therapy; clinical outcome

In the current era of antimicrobial resistance, the family Enterobacteriaceae is one of the most problematic groups of pathogens. Many classes of antimicrobial agents used to be almost uniformly active against Enterobacteriaceae, including $\beta$-lactam- $\beta$-lactamase inhibitor combinations, cephalosporins, carbapenems, sulfonamides, fluoroquinolones and aminoglycosides. However, resistance to these classes has worsened substantially in the last

Correspondence: Yohei Doi, MD, PhD, Division of Infectious Diseases, University of Pittsburgh School of Medicine, S829 Scaife Hall, 3550 Terrace Street, Pittsburgh, PA 15261; phone 412-648-9445, fax 412-648-8521, yod4@ pitt.edu.

*Current affiliation: Division of Infectious Diseases, Virginia Commonwealth University School of Medicine

Publisher's Disclaimer: This is a PDF file of an unedited manuscript that has been accepted for publication. As a service to our customers we are providing this early version of the manuscript. The manuscript will undergo copyediting, typesetting, and review of the resulting proof before it is published in its final citable form. Please note that during the production process errors may be discovered which could affect the content, and all legal disclaimers that apply to the journal pertain.

Potential conflict of interest

S.S has no potential conflicts of interest to declare. 
decade. Taking E. coli as an example as the prototypical and the most common

Enterobacteriaceae implicated in human infections, approximately half of those causing UTI among inpatients are now resistant to ampicillin-sulbactam, a third are resistant to ciprofloxacin, and up to $10 \%$ are resistant to cephalosporins, primarily due to production of extended-spectrum- $\beta$-lactamase (ESBL) [1]. Notably, this worsening resistance with the spread of ESBL is occurring not only in healthcare-associated infections [2, 3] but also community-associated infections $[4,5]$.

Urinary tract infection (UTI) is an exceedingly common type of bacterial infection that affects healthy individuals as well as those with comorbidities around the world. It is estimated that one in every three women experience at least one episode of urinary tract infection (UTI) requiring treatment with antimicrobial agents by the age of 24 [6]. Given the increasing rates of resistance in urinary pathogens to agents commonly used to treat UTIs such as trimethoprim-sulfamethoxazole and ciprofloxacin, there has been a surging interest in identifying new treatment options or re-evaluate existing agents for the treatment of UTIs. One such agent is fosfomycin, which has been in existence for over four decades now. Its use has gained popularity especially since the Infectious Diseases Society of America (IDSA) and the European Society for Clinical Microbiology and Infectious Diseases (ESCMID) updated their guidelines for the treatment of acute uncomplicated UTI and pyelonephritis in women by recommending fosfomycin as one of the first-line agents for the treatment of uncomplicated UTIs in 2011 [7]. Fosfomycin is a phosphonic acid derivative that was first identified and reported from various strains of Streptomyces spp. in 1969 [8]. It has been in use in most European countries for many years, but was only approved by the Food and Drug Administration (FDA) in the United States to be used, in the oral form only, as fosfomycin tromethamine, for the treatment of uncomplicated cystitis in 1996.

This review article summarizes recent studies describing the mechanism of action and resistance, susceptibility testing, pharmacodynamics and pharmacokinetic properties, dosing considerations, and clinical outcome data related to the use of this agent, including infections caused by multidrug-resistant (MDR) or extensively drug-resistant (XDR) pathogens.

\section{Mechanism of action and resistance}

Fosfomycin was initially reported as phosphonomycin, a broad-spectrum cell wall synthesis inhibitor produced by Streptomyces fradiae, Streptomyces viridochromogenes, and Streptomyces wedmorensis from the Merck, Sharp \& Dohme Research Laboratories in 1969 [8]. Fosfomycin is in an antimicrobial class of its own and is structurally unrelated to any other agent currently approved for clinical use (Figure 1). Its mode of action is inactivation of the cytosolic N-acetylglucosamine enolpyruvyl transferase (MurA), thereby preventing the formation of $\mathrm{N}$-acetylmuramic acid from $\mathrm{N}$-acetylglucosamine and phosphoenolpyruvate, which is the initial step in peptidoglycan chain formation of the bacterial wall [9]. Hence, fosfomycin is bactericidal in nature. The mechanisms by which fosfomycin is transported across the bacterial permeability barrier have been well described. Fosfomycin primarily utilizes the glycerol-3-phosphate transport system (GlpT) as a method of entry in almost all susceptible bacteria [10]. In addition, the hexose phosphate uptake 
transport system (UhpT) is induced in the presence of glucose-6-phosphate, providing an alternative to the GlpT system for its influx into cells [11].

Key resistance mechanisms to fosfomycin include the loss or reduced production of these functional transporters, reduced affinity to MurA and production of fosfomycin-modifying enzymes (Table 1). The former two mechanisms are chromosomal, whereas the latter mechanism can be chromosomal or plasmid-mediated. Mutations or insertional inactivation in one or both of the chromosomally-encoded transporter genes ( $g l p T$ and/or $u h p T$ ) or their regulatory genes $u h p A, u h p B$ and $u h p C$ of the UhpT system can lead to the loss of function of these transporters and resistance to fosfomycin [12]. Modification of MurA, the target of the drug has also been reported to result in fosfomycin resistance. In E. coli, fosfomycin covalently binds to cysteine at position 115 of MurA. The substitution of cysteine with aspartate in this active site has been shown to result in resistance to fosfomycin [13, 14]. The overexpression of MurA is another mechanism that can contribute to the development of a fosfomycin-resistant phenotype [15]. However, resistance due to MurA modification or overexpression appears to be rarer compared with the aforementioned transporter-mediated mechanisms.

Fosfomycin-modifying enzymes can be chromosomally encoded but are may also be encoded on transferable plasmids, especially in E. coli $[16,17]$. Three of the four known groups of fosfomycin modifying enzymes, namely FosA, FosB, and FosX, function by nucleophilic attack on carbon atom 1 of fosfomycin to open the epoxide ring thus rendering the drug inactive. The enzymes encoded by these genes differ by the identity of the nucleophile utilized in the reaction: glutathione for FosA [18], bacillithiol for FosB [19], and water for FosX [20]. In general, FosA and FosX enzymes are produced by Gram-negative bacteria, whereas FosB is produced by Gram-positive bacteria. Another group of plasmidmediated fosfomycin modifying enzymes, FosC, utilizes ATP and adds a phosphate group to fosfomycin, thus altering its properties and inactivating the drug [21].

Among these groups of Fos enzymes, the most concerning from an epidemiological standpoint is plasmid-mediated FosA3 in E. coli. FosA3 was initially reported from an $E$. coli clinical strain identified in Japan in 2006 [22], but has subsequently been shown to be widespread in East Asia (China, Hong Kong, Korea and Japan), in ESBL-producing E. coli and less commonly in K. pneumoniae from humans as well as food animals and pets [2327]. The fos $A 3$ gene is typically located on a composite transposon bounded by two copies of IS 26 on a conjugative plasmid that also carries a CTX-M-type ESBL [28]. Therefore, $E$. coli that acquires such a plasmid becomes resistant to cephalosporins and fosfomycin simultaneously. More recently, 34\% of KPC-producing K. pneumoniae collected from hospitals in China were shown to be resistant to fosfomycin and carried fosA3 [29]. Sequencing of a representative plasmid showed $b a_{\mathrm{KPC}-2}$ and $f o s A 3$ to be located on the same plasmid, which is worrisome since fosfomycin may be lost as a potential treatment option for KPC-producing organisms if such plasmids continue to spread.

Another Fos enzyme of potential concern is FosB3 in Enterococcus faecium which is reported in China [30]. fos $B 3$ can be co-located with van $A$ on self-transmissible plasmids; therefore, acquisition of such plasmids can result in simultaneous resistance to fosfomycin 
and vancomycin [31]. Some fosfomycin-resistant Staphylcoccus strains including Staphylococcus aureus carry plasmid-mediated fos $B$, though data are limited on this topic $[32,33]$.

\section{Susceptibility testing}

Susceptibility testing of fosfomycin merits attention (Table 2). The Clinical and Laboratory Standards Institute (CLSI) endorses reporting of fosfomycin susceptibility for urinary tract isolates of E. coli and Enterococcus faecalis with the use of agar dilution method or disk diffusion method [34]. The current susceptibility breakpoint of fosfomycin is $\leq 64 \mu \mathrm{g} / \mathrm{ml}$ for MIC and $\geq 16 \mathrm{~mm}$ for disk diffusion. The agar dilution method should be performed with Mueller-Hinton agar medium supplemented with $25 \mu \mathrm{g} / \mathrm{ml}$ of glucose-6-phosphate to reduce the rates of false resistance [35]. For disk diffusion testing and Etest, the addition of glucose-6-phosphate in the medium is not required since the disks and the gradient strips are supplemented with it. The European Committee on Antimicrobial Susceptibility Testing (EUCAST) defines the susceptibility breakpoint as $\leq 32 \mu \mathrm{g} / \mathrm{ml}$ for Enterobacteriaceae and Staphylococcus spp. (the latter for intravenous formulation only) (http://www.EUCAST.org). Addition of glucose-6-phosphate is required under the EUCAST guidelines as well. The testing methods (agar dilution, disk diffusion and Etest) appear to correlate well among contemporary gram-negative clinical isolates, with some Etest and agar dilution results not in essential agreement but not resulting in significant major or very major error rates [36], while some data suggest that disk diffusion testing and Etest may undercall resistance for carbapenem-resistant $P$. aeruginosa [37] and Enterobacteriaceae [38].

One practical challenge in interpreting the results of diffusion based methods (Etest and disk diffusion) is the frequent observation of scattered colonies within the inhibition zones [38, 39]. The CLSI recommends measuring the colony-free inner zone as long as contamination is ruled out, whereas some investigators have taken an approach where scattered colonies were taken into account only if they were in a density of $>5$ colonies per $\mathrm{cm}^{2}$ [38]. There has not been a consensus on this topic since its clinical significance has not been established. Therefore, confirmation with the reference agar dilution method is recommended when Etest or disk diffusion cannot be interpreted reliably.

\section{Spectrum of activity}

Fosfomycin is a broad-spectrum agent which has been shown to have excellent bactericidal activity against a range of gram-positive as well as gram-negative organisms, including drug-resistant varieties [40]. Since the epidemiology of antimicrobial resistance is changing rapidly, the studies published in the $21^{\text {st }}$ century are referenced below.

\section{Activity against Gram-positive organisms}

Fosfomycin is broadly active against methicillin-susceptible and -resistant $S$. aureus (MRSA) with a modal MIC of about $1 \mu \mathrm{g} / \mathrm{ml}$ [41], but there may be a subset of highly resistant strains among MRSA [40]. It is also active against the majority of coagulasenegative Staphylococcus spp., but not as predictably as with $S$. aureus [41]. 
Fosfomycin is active in vitro against most $E$. faecalis strains and the majority of vancomycin-resistant $E$. faecium (VRE) strains with modal MICs of 32 to $64 \mu \mathrm{g} / \mathrm{ml}[36,42$, 43]. Unlike with $S$. aureus, high-level resistance in enterococci appears uncommon. Susceptibility of streptococcal species including Streptococcus pneumoniae, Streptococcus pyogenes and Streptococcus agalactiae are variable [36, 40, 41].

\section{Activity against Gram-negative organisms}

Fosfomycin has excellent activity against $E$. coli, the primary UTI pathogen, based on in vitro data available from various countries including the U.S. with the susceptibility to fosfomycin ranging between 98 and 100\% [44-50]. Fosfomycin has shown good in vitro activity against $K$. pneumoniae with susceptibility rates between 70 and $85 \%$ and slightly higher susceptibility rates of 80 to $97 \%$ against Proteus mirabilis [44, 49]. Importantly, fosfomycin has excellent activity against extended-spectrum $\beta$-lactamase (ESBL)-producing Enterobacteriaceae [44, 49, 51]. For example, against ESBL-producing E. coli, fosfomycin had susceptibility rates of 86 to $100 \%$ [49, 52, 53], which were generally higher than those seen with nitrofurantoin, ciprofloxacin or trimethoprim-sulfamethoxazole [54, 55]. However, in a study performed in Spain between 2005 and 2009, a strong correlation was observed between the use of fosfomycin among outpatients and fosfomycin resistance in ESBLproducing E. coli from UTI cases (from $4.4 \%$ in 2005 to $11.4 \%$ in 2009), suggesting that resistance rates may rise as more fosfomycin is used clinically.

In a review of 17 studies that evaluated the antimicrobial activity and clinical effectiveness of fosfomycin for infections caused by multidrug-resistant (MDR) Enterobacteriaceae, including ESBL-producing organisms, 11 studies reported that at least $90 \%$ of the isolates were susceptible to fosfomycin [56]. Using the CLSI susceptibility breakpoint of $64 \mu \mathrm{g} / \mathrm{ml}$, the majority of ESBL-producing E. coli and $K$. pneumoniae isolates were susceptible to fosfomycin ( $97 \%$ and $81 \%$, respectively).

There is a growing interest in potential use of fosfomycin for the treatment of infections caused by carbapenem-resistant Enterobacteriaceae, such as KPC-producing K. pneumoniae. In studies from the U.S., 86 to $93 \%$ of KPC-producing $K$. pneumoniae isolates, including those non-susceptible to tigecycline or colistin, were susceptible to fosfomycin [57, 58], but only $67 \%$ of carbapenem-resistant $K$. pneumoniae were susceptible in a U.K. study [59]. In practice, fosfomycin is expected to be used in combination with other active agents in this scenario. Synergy has been observed between fosfomycin and meropenem in the majority of KPC-producing $K$. pneumoniae strains tested by the time-kill method [60].

Proteus spp., Enterobacter spp., Citrobacter spp., Serratia marcescens and Salmonella enterica are also generally susceptible to fosfomycin [41, 44]. For Pseudomonas aeruginosa and Stenotrophomonas maltophilia, the MICs cluster around $64 \mu \mathrm{g} / \mathrm{ml}$, thus the interpretation will depend on the susceptibility breakpoint applied [36, 37, 40]. Acinetobacter baumannii and Morganella morganii are mostly resistant to fosfomycin [36, $40,44]$, thus its use would only be considered in the context of combination therapy, especially for $A$. baumannii. 


\section{Pharmacokinetic properties of fosfomycin}

Two fosfomycin salts are available for oral administration: fosfomycin tromethimine and fosfomycin calcium. Both salts are rapidly absorbed following oral administration, but the bioavailability is significantly better for fosfomycin tromethamine (40\%) than fosfomycin calcium (12\%) since fosfomycin calcium is inactivated by hydrolysis in the acidic gastric environment [61, 62]. Fosfomycin disodium is the only intravenous formulation available, marketed under different brand names and used extensively outside the U.S. This intravenous formulation is associated with a high sodium intake that could be a limitation in patients with heart failure or who are receiving hemodialysis [63].

Fosfomycin is a hydrophilic agent with negligible protein binding [64] and therefore is exclusively eliminated via glomerular filtration, with its clearance correlating well with the glomerular filtration rate [65]. After a single 3-gram dose, a maximum serum concentration $\left(C_{\max }\right)$ of 22 to $32 \mu \mathrm{g} / \mathrm{ml}$ is achieved in approximately 2 hours, with serum elimination halflife of 2.4 to 7.3 hours and area under the concentration-time curve of 145 to $228 \mu \mathrm{g} / \mathrm{ml} \cdot \mathrm{h}$ [66]. A high urine concentration ( 1,000 to $4,000 \mu \mathrm{g} / \mathrm{ml})$ is achieved and remains over 100 $\mu \mathrm{g} / \mathrm{ml}$ for 30 to 48 hours, which is the pharmacokinetic basis for the single-dose oral regimen [67]. The volume of distribution ( $V \mathrm{~d}$ ) after an oral dose is 40 to $136 \mathrm{~L}$ depending on studies [64]. A 4-gram intravenous infusion achieves $C_{\max }$ of 200 to $250 \mu \mathrm{g} / \mathrm{ml}$ and an 8gram dose $C_{\max }$ of 260 to $450 \mu \mathrm{g} / \mathrm{ml}$ [64]. In critically ill patients, the $V \mathrm{~d}$ can increase by as much as $50 \%$ due to increased capillary permeability, resulting in significantly lower maximum plasma concentrations during the dosing interval [68-70]. Hence, in critically ill patients, frequent and higher doses of fosfomycin over the first 24-48 hours may be beneficial in overcoming the increased $V \mathrm{~d}$ [69], but this needs to be balanced with variations in renal function, which is also common in the critical care settings [70].

The high penetration of fosfomycin leads to favorable distribution into many tissue types, including interstitial fluid of muscle [71] and soft tissue [72], infected lung tissue[73], heart valves [74], urinary bladder wall [75], prostate [76] and cerebral spinal fluid (CSF) [77]. However, it has highly variable abscess permeability, possibly necessitating multiple doses of fosfomycin to assist in exceeding the MICs of the target bacteria at the site of infection [78].

Renal impairment significantly decreases the excretion of fosfomycin since it is primarily eliminated via the urinary system. Therefore, doses should be reduced if the creatinine clearance is less than $50 \mathrm{ml} / \mathrm{min}$ [79]. Fosfomycin is eliminated by hemodialysis, but is largely retained between dialysis sessions, thus administration of 2 grams after hemodialysis and further administration after each subsequent hemodialysis session has been proposed for intravenous fosfomycin [80]. In patients receiving continuous renal replacement therapy (CRRT), peak and trough levels of fosfomycin are thought to be similar to plasma levels found in critically ill patients without renal replacement therapy or even healthy individuals [81]. After a 12-hour hemofiltration process, $77 \%$ of fosfomycin is expected to be removed, suggesting that its concentration is high enough at any time during CRRT to eradicate target pathogens. An intravenous dose of 8 grams every 12 hours is therefore recommended for patients on CRRT [81]. 


\section{Adverse effects}

Fosfomycin has a favorable safety profile in general, with the most common adverse event being mild gastrointestinal distress. The rate of these adverse events reported in the literature related to the use of oral fosfomycin vary between 2 and $6 \%$, with the higher rates associated with patients treated with more than one doses $[64,82,83]$. A recent report indicated a high rate of mild hypokalemia (26\%), suggesting that potassium monitoring may be prudent particularly when using prolonged courses of intravenous fosfomycin [82]. The effect on the intestinal flora after intake of a single 3-gram dose has not been well established. However, longer intravenous treatment ( 5 grams twice daily for 5 days) alters the intestinal flora significantly, mainly with a reduction of Enterobacteriaceae as noted in an older study conducted over two decades ago [84].

\section{Drug interactions}

Clinical data reporting drug interactions of fosfomycin with other agents are scarce. Nonetheless, metoclopramide, a gastrointestinal pro-motility agent, reduces the bioavailability of fosfomycin leading to lower serum concentration and urinary excretion of fosfomycin, whereas it has no effect on cimetidine [85]. Fosfomycin has been shown to ameliorate nephrotoxicity from nephrotoxic drugs in experimental models, including aminoglycosides [86], glycopeptides [87] and amphotericin B [88]. However, whether this observation translates to clinical benefits in reducing nephrotoxicity remains unknown.

\section{Clinical uses and indications}

The primary indication of oral fosfomycin is in the treatment of uncomplicated UTIs caused by common gram-negative organisms such as $E$. coli [89]. A large body of clinical trials data suggest the efficacy of the single-dose regimen to be similar to that of a single dose or 3 to 7-day courses of comparators including fluoroquinolones, trimethoprim-sulfamethoxazole, nitrofurantoin, amoxicillin-clavulanate and oral cephalosporins for the treatment of uncomplicated UTI [90]. More recently, a retrospective cohort study evaluating the use of oral fosfomycin among inpatients at a U.S. tertiary hospital between 2009 and 2013 found that, of the patients who received fosfomycin for rigorously defined UTI where the majority had E. coli as the causative organism, 74.8 to $89.9 \%$ had clinical success, with recurrent infection occurring in $4.3 \%$ of the patients [83]. Likewise, in a case-control study investigated risk factors of community-acquired infections caused by ESBL-producing $E$. coli in Spanish hospitals, the cure rate of patients with cystitis and treated with fosfomycin was 93\%, with all the isolates being susceptible to fosfomycin [4].

For complicated UTIs, administration of oral fosfomycin 3 grams every 2 to 3 days has been suggested anecdotally based on its pharmacokinetics [85]. In fact, efficacy and safety data regarding multiple dose regimens of oral fosfomycin remain extremely scarce. A prospective, uncontrolled, open-label study conducted in China evaluated the clinical and microbiological efficacy and safety of three 3-gram doses of fosfomycin tromethamine administered orally every 48 hours to treat complicated and uncomplicated lower UTIs [91]. The clinical efficacy rates at day 15 for acute uncomplicated cystitis, recurrent lower urinary 
tract infection and complicated lower urinary tract infection were $95 \%, 77 \%$ and $63 \%$, respectively, and the microbiological efficacy rates were $98 \%, 94 \%$ and $84 \%$, respectively. In a case series of complicated and uncomplicated UTIs caused by MDR organisms (including ESBL and KPC-producing $K$. pneumoniae and E. coli, P. aeruginosa and VRE), patients received an average of 2.9 doses of fosfomycin, resulting in a microbiological cure rate of $59 \%$ despite $86 \%$ in vitro susceptibility of the causative organisms [43].

Fosfomycin has reasonable intraprostatic concentrations following a 3-gram oral dose, making it an option for perioperative prophylaxis in prostate resection procedures when compared to the fluroquinolones $[92,93]$ and even possibly for the treatment of prostatitis caused by MDR organisms [76, 94]. Notably, once daily dosing was well tolerated while twice a day dosing was associated with fecal urgency and diarrhea in a patient with prostatitis [94].

UTIs are common during pregnancy due to hormonal and anatomo-physiological changes that facilitate the growth and dissemination of bacteria in the maternal urinary tract [95]. Although fosfomycin crosses the placental barrier, it appears to be safe for use during pregnancy [96] and is well tolerated [97]. A single dose of fosfomycin tromethamine has been shown to be as efficacious as cefuroxime or amoxicillin-clavulanate in randomized trials of uncomplicated UTI among pregnant women [98, 99]. Oral fosfomycin has also been shown to be effective in the prophylaxis of recurrent UTIs in a randomized trial comparing oral fosfomycin given every 10 days for 6 months when followed for a period of 6 months (0.14 infections/patient year vs 2.97 infections/patient year in the placebo arm) [100].

In serious systemic infections other than uncomplicated UTI, intravenous fosfomycin is given at a dosage of 2 to $24 \mathrm{~g}$ a day divided in 3 to 4 doses, mostly in combination with other active agents $[64,101]$. Potential use of intravenous fosfomycin for the treatment of infections due to MRSA, VRE, and MDR gram-negative bacteria in combination with other agents has gained substantial interest due to its unique mechanism of action and potential protective effect against nephrotoxicity from aminoglycosides or colistin [63]. Intravenous fosfomycin has also been used to treat skin and soft tissue infections [102] as well as intraocular infections given the excellent diffusion of fosfomycin into the aqueous humor [103].

A 'real practice' multicenter, open-label, phase III randomized controlled trial coined FOREST (Fosfomycin versus meropenem in bactereaemic urinary tract infections caused by extended-spectrum $\beta$-lactamase-producing Escherichia coli) is ongoing in Spain [104]. The main objective of the study is to demonstrate the clinical non-inferiority of intravenous fosfomycin against meropenem for the treatment of bacteremic UTI caused by ESBLproducing E. coli. It is designed to compare the clinical and microbiological efficacy and safety of intravenous fosfomycin ( $4 \mathrm{~g}$ every 6 hours) and meropenem ( $1 \mathrm{~g}$ every 8 hours) as definitive therapy. The study is expected to provide high-quality clinical data on the feasibility of using intravenous fosfomycin for systemic ESBL-producing E. coli infections. 


\section{In vitro and clinical data on combination therapy for MDR infections}

Given the unique mechanism of action of fosfomycin, its use in combination with other agents is gaining popularity with many in vitro studies supporting the use, especially against MDR organisms in adults (see below) and even children [105]. Various combinations have been tested for in vitro synergy including fosfomycin-linezolid for treatment of MRSA infections [106], fosfomycin-amoxicillin and fosfomycin-daptomycin against VRE [107], fosfomycin-ceftriaxone against MDR Neisseria gonorrhoeae [108], fosfomycin-imipenem against MDR Pseudomonas aeruginosa [109], fosfomycin-colistin against XDR Acinetobacter baumanii [110] and amikacin-fosfomycin combination as a nebulized formulation against ventilator-associated pneumonia [111]. Promising results have also been shown in triple drug regimens with fosfomycin and other agents such as daptomycin, colistin, meropenem, rifampin, televancin, tigecyline and vancomycin against VIM- and NDM-producing $K$. pneumoniae by time-kill experiments [112].

A prospective evaluation to assess the safety and efficacy of fosfomycin as an adjunct to the therapy of life-threatening infections caused by carbapenem-resistant $K$. pneumoniae from Greece showed that all 11 patients had generally good clinical outcome of infection with 2 in-hospital deaths when fosfomycin was administered intravenously ( 2 to $4 \mathrm{~g}$ every $6 \mathrm{~h}$ ) for the treatment of hospital-acquired infections caused by this organism [63]. The partner agents were colistn (6), gentamicin (3) and piperacillin-tazobactam (1). Another retrospective study of trauma patients in Italy mirrored these results [113]. Using tigecycline as the backbone drug to treat KPC-producing $K$. pneumoniae infections with either colistin or gentamicin as the second drug, fosfomycin was given as the third drug in 13 of the 26 episodes. Overall, a favorable response to therapy was documented for $92 \%$ of the infectious episodes. In a case report from the U.S. where only oral fosfomycin is approved, bacteremia caused by KPC-producing $K$. pneumoniae in a bone marrow transplant patient, which was refractory to meropenem, gigecycline, amikacin and colistin, finally cleared with a combination of doxycycline, meropenem and high dose of oral fosfomycin ( $9 \mathrm{~g}$ every 8 hours) [114]. There is also a report of intravenous fosfomycin use in a U.S. hospital, where refractory bacteremia due to colistin-resistant carbapenem-resistant $K$. pneumoniae was treated with a combination of meropenem, amikacin, colistin, rifampin and intravenous fosfomycin imported from Europe, which led to resolution of bacteremia [115]. However, development of fosfomycin resistance during therapy has also been reported even in combination therapy, which may become a limiting factor in the use of fosfomycin in this context [116].

For methicillin-resistant $S$. aureus (MRSA), 16 patients with MRSA bacteremia or endocarditis who had failed treatment with vancomycin and/or daptomycin were treated with a combination of intravenous fosfomycin ( $2 \mathrm{~g}$ every 6 hours) and imipenem for a median of 28 days [117]. All patients achieved negative blood cultures within 72 hours, and 11 were cured at the test-of-cure visit. To confirm this promising finding, a multicenter, open-label randomized study is planned in Spain, where patients with MRSA bacteremia will be assigned to daptomycin alone or daptomycin plus fosfomycin ( $2 \mathrm{~g}$ every 6 hours) and followed for 6 weeks. The study is powered to demonstrate superiority of the latter approach with $20 \%$ difference in the cure rates. 


\section{Conclusions}

Fosfomycin has drawn significant attention in recent years due to its broad-spectrum activity that includes MDR gram-negative organisms such as ESBL-producing E. coli and, to some extent, KPC-producing $K$. pneumoniae. Its clinical efficacy for uncomplicated UTI is excellent, whereas clinical data on the treatment of more invasive infections are just beginning to emerge, both as stand-alone therapy and in combination therapy. Its potential use as an adjunct for the treatment of invasive MRSA infection is another application that appears promising. At the same time, emergence and spread of resistance, including transferable resistance, in some corners of the world is concerning and requires close monitoring. Overall, fosfomycin is expected to remain and be further harnessed as a critical component of the treatment armamentarium against MDR pathogens in the coming years.

\section{Acknowledgments}

The effort of Y.D. was supported by research grants from the National Institutes of Health (R01AI104895, R21AI107302).

Y.D. has served on an advisor board for Shionogi, Meiji, Tetraphase, consulted for Melinta Therapeutics, and received research funding from Merck and the Medicines Company for studies unrelated to this work.

\section{References}

1. Bouchillon SK, Badal RE, Hoban DJ, Hawser SP. Antimicrobial susceptibility of inpatient urinary tract isolates of gram-negative bacilli in the United States: results from the study for monitoring antimicrobial resistance trends (SMART) program: 2009-2011. Clin Ther. 2013; 35:872-877. [PubMed: 23623624]

2. Bradford PA. Extended-spectrum $\beta$-lactamases in the 21 st century: characterization, epidemiology, and detection of this important resistance threat. Clin Microbiol Rev. 2001; 14:933-951. [PubMed: 11585791]

3. Paterson DL, Bonomo RA. Extended-spectrum $\beta$-lactamases: a clinical update. Clin Microbiol Rev. 2005; 18:657-686. [PubMed: 16223952]

4. Rodriguez-Bano J, Alcala JC, Cisneros JM, Grill F, Oliver A, Horcajada JP, et al. Community infections caused by extended-spectrum $\beta$-lactamase-producing Escherichia coli. Arch Intern Med. 2008; 168:1897-1902. [PubMed: 18809817]

5. Doi Y, Park YS, Rivera JI, Adams-Haduch JM, Hingwe A, Sordillo EM, et al. Communityassociated extended-spectrum $\beta$-lactamase-producing Escherichia coli infection in the United States. Clin Infect Dis. 2013; 56:641-648. [PubMed: 23150211]

6. Foxman B. Epidemiology of urinary tract infections: incidence, morbidity, and economic costs. Am J Med. 2002; 113(Suppl 1A):5S-13S. [PubMed: 12113866]

7. Gupta K, Hooton TM, Naber KG, Wullt B, Colgan R, Miller LG, et al. International clinical practice guidelines for the treatment of acute uncomplicated cystitis and pyelonephritis in women: A 2010 update by the Infectious Diseases Society of America and the European Society for Microbiology and Infectious Diseases. Clin Infect Dis. 2011; 52:e103-e120. [PubMed: 21292654]

8. Hendlin D, Stapley EO, Jackson M, Wallick H, Miller AK, Wolf FJ, et al. Phosphonomycin, a new antibiotic produced by strains of streptomyces. Science. 1969; 166:122-123. [PubMed: 5809587]

9. Kahan FM, Kahan JS, Cassidy PJ, Kropp H. The mechanism of action of fosfomycin (phosphonomycin). Ann N Y Acad Sci. 1974; 235:364-386. [PubMed: 4605290]

10. Silhavy TJ, Hartig-Beecken I, Boos W. Periplasmic protein related to the sn-glycerol-3-phosphate transport system of Escherichia coli. J Bacteriol. 1976; 126:951-958. [PubMed: 770459]

11. Kadner RJ, Winkler HH. Isolation and characterization of mutations affecting the transport of hexose phosphates in Escherichia coli. J Bacteriol. 1973; 113:895-900. [PubMed: 4347928] 
12. Takahata S, Ida T, Hiraishi T, Sakakibara S, Maebashi K, Terada S, et al. Molecular mechanisms of fosfomycin resistance in clinical isolates of Escherichia coli. Int J Antimicrob Agents. 2010; 35:333-337. [PubMed: 20071153]

13. Kim DH, Lees WJ, Kempsell KE, Lane WS, Duncan K, Walsh CT. Characterization of a Cys115 to Asp substitution in the Escherichia coli cell wall biosynthetic enzyme UDP-GlcNAc enolpyruvyl transferase (MurA) that confers resistance to inactivation by the antibiotic fosfomycin. Biochemistry. 1996; 35:4923-4928. [PubMed: 8664284]

14. Venkateswaran PS, Wu HC. Isolation and characterization of a phosphonomycin-resistant mutant of Escherichia coli K-12. J Bacteriol. 1972; 110:935-944. [PubMed: 4555418]

15. Horii T, Kimura T, Sato K, Shibayama K, Ohta M. Emergence of fosfomycin-resistant isolates of Shiga-like toxin-producing Escherichia coli O26. Antimicrob Agents Chemother. 1999; 43:789793. [PubMed: 10103182]

16. Arca P, Rico M, Brana AF, Villar CJ, Hardisson C, Suarez JE. Formation of an adduct between fosfomycin and glutathione: a new mechanism of antibiotic resistance in bacteria. Antimicrob Agents Chemother. 1988; 32:1552-1556. [PubMed: 3056239]

17. Arca P, Reguera G, Hardisson C. Plasmid-encoded fosfomycin resistance in bacteria isolated from the urinary tract in a multicentre survey. J Antimicrob Chemother. 1997; 40:393-399. [PubMed: 9338493]

18. Bernat BA, Laughlin LT, Armstrong RN. Fosfomycin resistance protein (FosA) is a manganese metalloglutathione transferase related to glyoxalase I and the extradiol dioxygenases. Biochemistry. 1997; 36:3050-3055. [PubMed: 9115979]

19. Roberts AA, Sharma SV, Strankman AW, Duran SR, Rawat M, Hamilton CJ. Mechanistic studies of FosB: a divalent-metal-dependent bacillithiol-S-transferase that mediates fosfomycin resistance in Staphylococcus aureus. Biochem J. 2013; 451:69-79. [PubMed: 23256780]

20. Fillgrove KL, Pakhomova S, Newcomer ME, Armstrong RN. Mechanistic diversity of fosfomycin resistance in pathogenic microorganisms. J Am Chem Soc. 2003; 125:15730-15731. [PubMed: 14677948]

21. Garcia P, Arca P, Evaristo Suarez J. Product of fosC, a gene from Pseudomonas syringae, mediates fosfomycin resistance by using ATP as cosubstrate. Antimicrob Agents Chemother. 1995; 39:1569-1573. [PubMed: 7492106]

22. Wachino J, Yamane K, Suzuki S, Kimura K, Arakawa Y. Prevalence of fosfomycin resistance among CTX-M-producing Escherichia coli clinical isolates in Japan and identification of novel plasmid-mediated fosfomycin-modifying enzymes. Antimicrob Agents Chemother. 2010; 54:3061-3064. [PubMed: 20404116]

23. Lee SY, Park YJ, Yu JK, Jung S, Kim Y, Jeong SH, et al. Prevalence of acquired fosfomycin resistance among extended-spectrum $\beta$-lactamase-producing Escherichia coli and Klebsiella pneumoniae clinical isolates in Korea and IS 26-composite transposon surrounding fos A3. J Antimicrob Chemother. 2012; 67:2843-2847. [PubMed: 22893681]

24. Hou J, Huang X, Deng Y, He L, Yang T, Zeng Z, et al. Dissemination of the fosfomycin resistance gene fos $A 3$ with CTX-M $\beta$-lactamase genes and $r m t B$ carried on IncFII plasmids among Escherichia coli isolates from pets in China. Antimicrob Agents Chemother. 2012; 56:2135-2138. [PubMed: 22232290]

25. Hou J, Yang X, Zeng Z, Lv L, Yang T, Lin D, et al. Detection of the plasmid-encoded fosfomycin resistance gene fosA3 in Escherichia coli of food-animal origin. J Antimicrob Chemother. 2013; 68:766-770. [PubMed: 23190765]

26. Ho PL, Chan J, Lo WU, Law PY, Li Z, Lai EL, et al. Dissemination of plasmid-mediated fosfomycin resistance fos $A 3$ among multidrug-resistant Escherichia coli from livestock and other animals. J Appl Microbiol. 2013; 114:695-702. [PubMed: 23216653]

27. Ho PL, Chan J, Lo WU, Lai EL, Cheung YY, Lau TC, et al. Prevalence and molecular epidemiology of plasmid-mediated fosfomycin resistance genes among blood and urinary Escherichia coli isolates. J Med Microbiol. 2013; 62:1707-1713. [PubMed: 23988630]

28. Yang X, Liu W, Liu Y, Wang J, Lv L, Chen X, et al. F33: A-: B-, IncHI2/ST3, and IncI1/ST71 plasmids drive the dissemination of fos A3 and bla CTX-M-55/-14/-65 in Escherichia coli from chickens in China. Front Microbiol. 2014; 5:688. [PubMed: 25566207] 
29. Jiang Y, Shen P, Wei Z, Liu L, He F, Shi K, et al. Dissemination of a clone carrying a fosA3harbouring plasmid mediates high fosfomycin resistance rate of KPC-producing Klebsiella pneumoniae in China. Int J Antimicrob Agents. 2015; 45:66-70. [PubMed: 25450805]

30. Chen C, Xu X, Qu T, Yu Y, Ying C, Liu Q, et al. Prevalence of the fosfomycin-resistance determinant, fosB3, in Enterococcus faecium clinical isolates from China. J Med Microbiol. 2014; 63:1484-1489. [PubMed: 25102907]

31. Xu X, Chen C, Lin D, Guo Q, Hu F, Zhu D, et al. The fosfomycin resistance gene fosB3 is located on a transferable, extrachromosomal circular intermediate in clinical Enterococcus faecium isolates. PLoS One. 2013; 8:e78106. [PubMed: 24205114]

32. Etienne J, Gerbaud G, Fleurette J, Courvalin P. Characterization of staphylococcal plasmids hybridizing with the fosfomycin resistance gene fosB. FEMS Microbiol Lett. 1991; 68:119-122. [PubMed: 1769548]

33. Takeuchi F, Watanabe S, Baba T, Yuzawa H, Ito T, Morimoto Y, et al. Whole-genome sequencing of Staphylococcus haemolyticus uncovers the extreme plasticity of its genome and the evolution of human-colonizing staphylococcal species. J Bacteriol. 2005; 187:7292-7308. [PubMed: 16237012]

34. Clinical and Laboratory Standards Institute. Performance standards for antimicrobial susceptibility testing; twenty-fifth informational supplement. Wayne, PA: 2015.

35. Barry AL, Fuchs PC. In vitro susceptibility testing procedures for fosfomycin tromethamine. Antimicrob Agents Chemother. 1991; 35:1235-1238. [PubMed: 1929270]

36. Hirsch EB, Raux BR, Zucchi PC, Kim Y, McCoy C, Kirby JE, et al. Activity of fosfomycin and comparison of several susceptibility testing methods against contemporary urine isolates. Int $\mathrm{J}$ Antimicrob Agents. 2015

37. Perdigao-Neto LV, Oliveira MS, Rizek CF, Carrilho CM, Costa SF, Levin AS. Susceptibility of multiresistant gram-negative bacteria to fosfomycin and performance of different susceptibility testing methods. Antimicrob Agents Chemother. 2014; 58:1763-1767. [PubMed: 24323469]

38. Kaase M, Szabados F, Anders A, Gatermann SG. Fosfomycin susceptibility in carbapenemresistant Enterobacteriaceae from Germany. J Clin Microbiol. 2014; 52:1893-1897. [PubMed: 24648559]

39. Diez-Aguilar M, Morosini MI, del Campo R, Garcia-Castillo M, Zamora J, Canton R. In vitro activity of fosfomycin against a collection of clinical Pseudomonas aeruginosa isolates from 16 Spanish hospitals: establishing the validity of standard broth microdilution as susceptibility testing method. Antimicrob Agents Chemother. 2013; 57:5701-5703. [PubMed: 23939889]

40. Lu CL, Liu CY, Huang YT, Liao CH, Teng LJ, Turnidge JD, et al. Antimicrobial susceptibilities of commonly encountered bacterial isolates to fosfomycin determined by agar dilution and disk diffusion methods. Antimicrob Agents Chemother. 2011; 55:4295-4301. [PubMed: 21670185]

41. Falagas ME, Maraki S, Karageorgopoulos DE, Kastoris AC, Kapaskelis A, Samonis G. Antimicrobial susceptibility of Gram-positive non-urinary isolates to fosfomycin. Int J Antimicrob Agents. 2010; 35:497-499. [PubMed: 20226634]

42. Pogue JM, Marchaim D, Abreu-Lanfranco O, Sunkara B, Mynatt RP, Zhao JJ, et al. Fosfomycin activity versus carbapenem-resistant Enterobacteriaceae and vancomycin-resistant Enterococcus, Detroit, 2008-10. J Antibiot (Tokyo). 2013; 66:625-627. [PubMed: 23715037]

43. Neuner EA, Sekeres J, Hall GS, van Duin D. Experience with fosfomycin for treatment of urinary tract infections due to multidrug-resistant organisms. Antimicrob Agents Chemother. 2012; 56:5744-5748. [PubMed: 22926565]

44. Demir T, Buyukguclu T. Evaluation of the in vitro activity of fosfomycin tromethamine against Gram-negative bacterial strains recovered from community- and hospital-acquired urinary tract infections in Turkey. Int J Infect Dis. 2013; 17:e966-e970. [PubMed: 23742831]

45. Naber KG, Schito G, Botto H, Palou J, Mazzei T. Surveillance study in Europe and Brazil on clinical aspects and Antimicrobial Resistance Epidemiology in Females with Cystitis (ARESC): implications for empiric therapy. Eur Urol. 2008; 54:1164-1175. [PubMed: 18511178]

46. Biondo CM, Rocha JL, Tuon FF. Fosfomycin in vitro resistance of Escherichia coli from the community. Braz J Infect Dis. 2011; 15:96. [PubMed: 21412601] 
47. Karlowsky JA, Denisuik AJ, Lagace-Wiens PR, Adam HJ, Baxter MR, Hoban DJ, et al. In vitro activity of fosfomycin against Escherichia coli isolated from patients with urinary tract infections in Canada as part of the CANWARD surveillance study. Antimicrob Agents Chemother. 2014; 58:1252-1256. [PubMed: 24323476]

48. Gobernado M, Valdes L, Alos JI, Garcia-Rey C, Dal-Re R, Garcia-de-Lomas J, et al. Antimicrobial susceptibility of clinical Escherichia coli isolates from uncomplicated cystitis in women over a 1year period in Spain. Rev Esp Quimioter. 2007; 20:68-76. [PubMed: 17530038]

49. Maraki S, Samonis G, Rafailidis PI, Vouloumanou EK, Mavromanolakis E, Falagas ME. Susceptibility of urinary tract bacteria to fosfomycin. Antimicrob Agents Chemother. 2009; 53:4508-4510. [PubMed: 19687248]

50. Johnson JR, Drawz SM, Porter S, Kuskowski MA. Susceptibility to alternative oral antimicrobial agents in relation to sequence type ST131 status and coresistance phenotype among recent Escherichia coli isolates from U.S. veterans. Antimicrob Agents Chemother. 2013; 57:4856-4860. [PubMed: 23877695]

51. Hutley EJ, Chand MA, Hounsome G, Kelsey MC. Fosfomycin: an oral agent for urinary infection caused by extended spectrum $\beta$-lactamase producing organisms. J Infect. 2010; 60:308-309. [PubMed: 20114062]

52. Liu HY, Lin HC, Lin YC, Yu SH, Wu WH, Lee YJ. Antimicrobial susceptibilities of urinary extended-spectrum $\beta$-lactamase-producing Escherichia coli and Klebsiella pneumoniae to fosfomycin and nitrofurantoin in a teaching hospital in Taiwan. J Microbiol Immunol Infect. 2011; 44:364-368. [PubMed: 21524974]

53. Araj GF, Jaber FA. In vitro activity of fosfomycin and other antimicrobials against uropathogenic Escherichia coli and Klebsiella pneumoniae at a tertiary care center in Lebanon. J Med Liban. 2012; 60:142-147. [PubMed: 23198454]

54. Saltoglu N, Karali R, Yemisen M, Ozaras R, Balkan II, Mete B, et al. Comparison of communityonset healthcare-associated and hospital-acquired urinary infections caused by extended-spectrum $\beta$-lactamase-producing Escherichia coli and antimicrobial activities. Int J Clin Pract. 2015; 69:766-770. [PubMed: 25683907]

55. Keating GM. Fosfomycin trometamol: a review of its use as a single-dose oral treatment for patients with acute lower urinary tract infections and pregnant women with asymptomatic bacteriuria. Drugs. 2013; 73:1951-1966. [PubMed: 24202878]

56. Falagas ME, Kastoris AC, Kapaskelis AM, Karageorgopoulos DE. Fosfomycin for the treatment of multidrug-resistant, including extended-spectrum $\beta$-lactamase producing, Enterobacteriaceae infections: a systematic review. Lancet Infect Dis. 2010; 10:43-50. [PubMed: 20129148]

57. Endimiani A, Patel G, Hujer KM, Swaminathan M, Perez F, Rice LB, et al. In vitro activity of fosfomycin against bla $\mathrm{KPC}^{-c o n t a i n i n g ~ K l e b s i e l l a ~ p n e u m o n i a e ~ i s o l a t e s, ~ i n c l u d i n g ~ t h o s e ~}$ nonsusceptible to tigecycline and/or colistin. Antimicrob Agents Chemother. 2010; 54:526-529. [PubMed: 19901089]

58. Alexander BT, Marschall J, Tibbetts RJ, Neuner EA, Dunne WM Jr, Ritchie DJ. Treatment and clinical outcomes of urinary tract infections caused by KPC-producing Enterobacteriaceae in a retrospective cohort. Clin Ther. 2012; 34:1314-1323. [PubMed: 22691610]

59. Livermore DM, Warner M, Mushtaq S, Doumith M, Zhang J, Woodford N. What remains against carbapenem-resistant Enterobacteriaceae? Evaluation of chloramphenicol, ciprofloxacin, colistin, fosfomycin, minocycline, nitrofurantoin, temocillin and tigecycline. Int J Antimicrob Agents. 2011; 37:415-419. [PubMed: 21429716]

60. Souli M, Galani I, Boukovalas S, Gourgoulis MG, Chryssouli Z, Kanellakopoulou K, et al. In vitro interactions of antimicrobial combinations with fosfomycin against KPC-2-producing Klebsiella pneumoniae and protection of resistance development. Antimicrob Agents Chemother. 2011; 55:2395-2397. [PubMed: 21321144]

61. Bergan T. Degree of absorption, pharmacokinetics of fosfomycin trometamol and duration of urinary antibacterial activity. Infection. 1990; 18(Suppl 2):S65-S69. [PubMed: 2286464]

62. Zambon Switzerland Ltd. Monurol (fosfomycin tromethamine) package insert. St. Louis, MO: 2007. 
63. Michalopoulos A, Virtzili S, Rafailidis P, Chalevelakis G, Damala M, Falagas ME. Intravenous fosfomycin for the treatment of nosocomial infections caused by carbapenem-resistant Klebsiella pneumoniae in critically ill patients: a prospective evaluation. Clin Microbiol Infect. 2010; 16:184-186. [PubMed: 19694767]

64. Roussos N, Karageorgopoulos DE, Samonis G, Falagas ME. Clinical significance of the pharmacokinetic and pharmacodynamic characteristics of fosfomycin for the treatment of patients with systemic infections. Int J Antimicrob Agents. 2009; 34:506-515. [PubMed: 19828298]

65. Bergan T, Thorsteinsson SB, Albini E. Pharmacokinetic profile of fosfomycin trometamol. Chemotherapy. 1993; 39:297-301. [PubMed: 8370321]

66. Patel SS, Balfour JA, Bryson HM. Fosfomycin tromethamine. A review of its antibacterial activity, pharmacokinetic properties and therapeutic efficacy as a single-dose oral treatment for acute uncomplicated lower urinary tract infections. Drugs. 1997; 53:637-656. [PubMed: 9098664]

67. Mazzei T, Cassetta MI, Fallani S, Arrigucci S, Novelli A. Pharmacokinetic and pharmacodynamic aspects of antimicrobial agents for the treatment of uncomplicated urinary tract infections. Int J Antimicrob Agents. 2006; 28(Suppl 1):S35-S41. [PubMed: 16829051]

68. Lipman J, Udy AA, Roberts JA. Do we understand the impact of altered physiology, consequent interventions and resultant clinical scenarios in the intensive care unit? The antibiotic story. Anaesth Intensive Care. 2011; 39:999-1000. [PubMed: 22165348]

69. Parker S, Lipman J, Koulenti D, Dimopoulos G, Roberts JA. What is the relevance of fosfomycin pharmacokinetics in the treatment of serious infections in critically ill patients? A systematic review. Int J Antimicrob Agents. 2013; 42:289-293. [PubMed: 23880170]

70. Parker SL, Frantzeskaki F, Wallis SC, Diakaki C, Giamarellou H, Koulenti D, et al. Population pharmacokinetics of fosfomycin in critically ill patients. Antimicrob Agents Chemother. 2015; 59:6471-6476. [PubMed: 26239990]

71. Joukhadar C, Klein N, Dittrich P, Zeitlinger M, Geppert A, Skhirtladze K, et al. Target site penetration of fosfomycin in critically ill patients. J Antimicrob Chemother. 2003; 51:1247-1252. [PubMed: 12668580]

72. Frossard M, Joukhadar C, Erovic BM, Dittrich P, Mrass PE, Van Houte M, et al. Distribution and antimicrobial activity of fosfomycin in the interstitial fluid of human soft tissues. Antimicrob Agents Chemother. 2000; 44:2728-2732. [PubMed: 10991852]

73. Matzi V, Lindenmann J, Porubsky C, Kugler SA, Maier A, Dittrich P, et al. Extracellular concentrations of fosfomycin in lung tissue of septic patients. J Antimicrob Chemother. 2010; 65:995-998. [PubMed: 20228081]

74. Miro JM, Entenza JM, Del Rio A, Velasco M, Castaneda X, Garcia de la Maria C, et al. High-dose daptomycin plus fosfomycin is safe and effective in treating methicillin-susceptible and methicillin-resistant Staphylococcus aureus endocarditis. Antimicrob Agents Chemother. 2012; 56:4511-4515. [PubMed: 22644033]

75. Scaglione F, Cicchetti F, Demartini G, Arcidiacono M. Fosfomycin distribution in the lower urinary tract after administration of fosfomycin trometamol salt. Int J Clin Pharmacol Res. 1994; 14:107-109. [PubMed: 7883387]

76. Gardiner BJ, Mahony AA, Ellis AG, Lawrentschuk N, Bolton DM, Zeglinski PT, et al. Is fosfomycin a potential treatment alternative for multidrug-resistant gram-negative prostatitis? Clin Infect Dis. 2014; 58:e101-e105. [PubMed: 24170195]

77. Pfausler B, Spiss H, Dittrich P, Zeitlinger M, Schmutzhard E, Joukhadar C. Concentrations of fosfomycin in the cerebrospinal fluid of neurointensive care patients with ventriculostomyassociated ventriculitis. J Antimicrob Chemother. 2004; 53:848-852. [PubMed: 15056646]

78. Sauermann R, Karch R, Langenberger H, Kettenbach J, Mayer-Helm B, Petsch M, et al. Antibiotic abscess penetration: fosfomycin levels measured in pus and simulated concentration-time profiles. Antimicrob Agents Chemother. 2005; 49:4448-4454. [PubMed: 16251282]

79. Borsa F, Leroy A, Fillastre JP, Godin M, Moulin B. Comparative pharmacokinetics of tromethamine fosfomycin and calcium fosfomycin in young and elderly adults. Antimicrob Agents Chemother. 1988; 32:938-941. [PubMed: 3415215]

80. Bouchet JL, Quentin C, Albin H, Vincon G, Guillon J, Martin-Dupont P. Pharmacokinetics of fosfomycin in hemodialyzed patients. Clin Nephrol. 1985; 23:218-221. [PubMed: 4006330] 
81. Gattringer R, Meyer B, Heinz G, Guttmann C, Zeitlinger M, Joukhadar C, et al. Single-dose pharmacokinetics of fosfomycin during continuous venovenous haemofiltration. J Antimicrob Chemother. 2006; 58:367-371. [PubMed: 16782745]

82. Florent A, Chichmanian RM, Cua E, Pulcini C. Adverse events associated with intravenous fosfomycin. Int J Antimicrob Agents. 2011; 37:82-83. [PubMed: 21074377]

83. Sastry S, Clarke LG, Alrowais H, Querry AM, Shutt KA, Doi Y. Clinical appraisal of fosfomycin in the era of antimicrobial resistance. Antimicrob Agents Chemother. 2015; 59:7355-7361. [PubMed: 26369978]

84. Knothe H, Schafer V, Sammann A, Shah PM. Influence of fosfomycin on the intestinal and pharyngeal flora of man. Infection. 1991; 19:18-20. [PubMed: 2013503]

85. Frimodt-Møller, N. Fosfomycin. In: Grayson, ML.; Crowe, SM.; McCarthy, JS.; Mills, J.; Mouton, JW.; Norrby, SR., et al., editors. Kucer's the use of antibiotics. London: Hodder Arnold; 2010. p. 935-944.

86. Inouye S, Niizato T, Takeda U, Koeda T. Protective effect of fosfomycin on the experimental nephrotoxicity induced by dibekacin. J Pharmacobiodyn. 1982; 5:659-669. [PubMed: 7153839]

87. Yoshiyama Y, Yazaki T, Wong PC, Beauchamp D, Kanke M. The effect of fosfomycin on glycopeptide antibiotic-induced nephrotoxicity in rats. J Infect Chemother. 2001; 7:243-246. [PubMed: 11810591]

88. Kreft B, de Wit C, Marre R, Sack K. Experimental studies on the nephrotoxicity of amphotericin B in rats. J Antimicrob Chemother. 1991; 28:271-281. [PubMed: 1778857]

89. Michalopoulos AS, Livaditis IG, Gougoutas V. The revival of fosfomycin. Int J Infect Dis. 2011; 15:e732-e739. [PubMed: 21945848]

90. Falagas ME, Vouloumanou EK, Togias AG, Karadima M, Kapaskelis AM, Rafailidis PI, et al. Fosfomycin versus other antibiotics for the treatment of cystitis: a meta-analysis of randomized controlled trials. J Antimicrob Chemother. 2010; 65:1862-1877. [PubMed: 20587612]

91. Qiao LD, Zheng B, Chen S, Yang Y, Zhang K, Guo HF, et al. Evaluation of three-dose fosfomycin tromethamine in the treatment of patients with urinary tract infections: an uncontrolled, open-label, multicentre study. BMJ Open. 2013; 3:e004157.

92. Rhodes NJ, Gardiner BJ, Neely MN, Grayson ML, Ellis AG, Lawrentschuk N, et al. Optimal timing of oral fosfomycin administration for pre-prostate biopsy prophylaxis. J Antimicrob Chemother. 2015; 70:2068-2073. [PubMed: 25802286]

93. Ongun S, Aslan G, Avkan-Oguz V. The effectiveness of single-dose fosfomycin as antimicrobial prophylaxis for patients undergoing transrectal ultrasound-guided biopsy of the prostate. Urol Int. 2012; 89:439-444. [PubMed: 23006631]

94. Grayson ML, Macesic N, Trevillyan J, Ellis AG, Zeglinski PT, Hewitt NH, et al. Fosfomycin for treatment of prostatitis: New tricks for old dogs. Clin Infect Dis. 2015; 61:1141-1143. [PubMed: 26063723]

95. Fiadjoe P, Kannan K, Rane A. Maternal urological problems in pregnancy. Eur J Obstet Gynecol Reprod Biol. 2010; 152:13-17. [PubMed: 20483528]

96. Stein GE. Fosfomycin tromethamine: single-dose treatment of acute cystitis. Int J Fertil Womens Med. 1999; 44:104-109. [PubMed: 10338268]

97. Krcmery S, Hromec J, Demesova D. Treatment of lower urinary tract infection in pregnancy. Int J Antimicrob Agents. 2001; 17:279-282. [PubMed: 11295408]

98. Usta TA, Dogan O, Ates U, Yucel B, Onar Z, Kaya E. Comparison of single-dose and multipledose antibiotics for lower urinary tract infection in pregnancy. Int J Gynaecol Obstet. 2011; 114:229-233. [PubMed: 21696732]

99. Bayrak O, Cimentepe E, Inegol I, Atmaca AF, Duvan CI, Koc A, et al. Is single-dose fosfomycin trometamol a good alternative for asymptomatic bacteriuria in the second trimester of pregnancy? Int Urogynecol J Pelvic Floor Dysfunct. 2007; 18:525-529. [PubMed: 16941068]

100. Rudenko N, Dorofeyev A. Prevention of recurrent lower urinary tract infections by long-term administration of fosfomycin trometamol. Double blind, randomized, parallel group, placebo controlled study. Arzneimittelforschung. 2005; 55:420-427. [PubMed: 16080282]

101. Falagas ME, Giannopoulou KP, Kokolakis GN, Rafailidis PI. Fosfomycin: use beyond urinary tract and gastrointestinal infections. Clin Infect Dis. 2008; 46:1069-1077. [PubMed: 18444827] 
102. Legat FJ, Maier A, Dittrich P, Zenahlik P, Kern T, Nuhsbaumer S, et al. Penetration of fosfomycin into inflammatory lesions in patients with cellulitis or diabetic foot syndrome. Antimicrob Agents Chemother. 2003; 47:371-374. [PubMed: 12499216]

103. Forestier F, Salvanet-Bouccara A, Leveques D, Junes P, Rakotondrainy C, Dublanchet A, et al. Ocular penetration kinetics of fosfomycin administered as a one-hour infusion. Eur J Ophthalmol. 1996; 6:137-142. [PubMed: 8823585]

104. Rosso-Fernandez C, Sojo-Dorado J, Barriga A, Lavin-Alconero L, Palacios Z, Lopez-Hernandez I, et al. Fosfomycin versus meropenem in bacteraemic urinary tract infections caused by extended-spectrum $\beta$-lactamase-producing Escherichia coli (FOREST): study protocol for an investigator-driven randomised controlled trial. BMJ Open. 2015; 5:e007363.

105. Wu TH, Huang FL, Fu LS, Chou CM, Chien YL, Huang CM, et al. Treatment of recurrent complicated urinary tract infections in children with vesicoureteral reflux. J Microbiol Immunol Infect. 2014

106. Xu-hong Y, Falagas ME, Dong W, Karageorgopoulos DE, De-feng L, Rui W. In vitro activity of fosfomycin in combination with linezolid against clinical isolates of methicillin-resistant Staphylococcus aureus. J Antibiot (Tokyo). 2014; 67:369-371. [PubMed: 24517925]

107. Descourouez JL, Jorgenson MR, Wergin JE, Rose WE. Fosfomycin synergy in vitro with amoxicillin, daptomycin, and linezolid against vancomycin-resistant Enterococcus faecium from renal transplant patients with infected urinary stents. Antimicrob Agents Chemother. 2013; 57:1518-1520. [PubMed: 23263002]

108. Hauser C, Hirzberger L, Unemo M, Furrer H, Endimiani A. In vitro activity of fosfomycin alone and in combination with ceftriaxone or azithromycin against clinical Neisseria gonorrhoeae isolates. Antimicrob Agents Chemother. 2015; 59:1605-1611. [PubMed: 25547354]

109. Santos DA, Nascimento MM, Vitali LH, Martinez R. In vitro activity of antimicrobial combinations against multidrug-resistant Pseudomonas aeruginosa. Rev Soc Bras Med Trop. 2013; 46:299-303. [PubMed: 23856877]

110. Wei W, Yang H, Liu Y, Ye Y, Li J. In vitro synergy of colistin combinations against extensively drug-resistant Acinetobacter baumannii producing OXA-23 carbapenemase. J Chemother. 2015 1973947815 Y0000000030.

111. Montgomery AB, Rhomberg PR, Abuan T, Walters KA, Flamm RK. Amikacin-fosfomycin at a five-to-two ratio: characterization of mutation rates in microbial strains causing ventilatorassociated pneumonia and interactions with commonly used antibiotics. Antimicrob Agents Chemother. 2014; 58:3708-3713. [PubMed: 24752276]

112. Tangden T, Hickman RA, Forsberg P, Lagerback P, Giske CG, Cars O. Evaluation of double- and triple-antibiotic combinations for VIM- and NDM-producing Klebsiella pneumoniae by in vitro time-kill experiments. Antimicrob Agents Chemother. 2014; 58:1757-1762. [PubMed: 24395223]

113. Sbrana F, Malacarne P, Viaggi B, Costanzo S, Leonetti P, Leonildi A, et al. Carbapenem-sparing antibiotic regimens for infections caused by Klebsiella pneumoniae carbapenemase-producing $K$. pneumoniae in intensive care unit. Clin Infect Dis. 2013; 56:697-700. [PubMed: 23155147]

114. Kyle JM, Stollings JL, White KD, Noto MJ, Wheeler AP. Fosfomycin for multidrug treatment of Klebsiella pneumoniae carbapenemase bacteremia. Ann Pharmacother. 2015; 49:366-367. [PubMed: 25691478]

115. Simkins J, Fan J, Camargo JF, Aragon L, Frederick C. Intravenous fosfomycin treatment for carbapenem-resistant Klebsiella pneumoniae in the United States. Ann Pharmacother. 2015; 49:1177-1178. [PubMed: 26238469]

116. Karageorgopoulos DE, Miriagou V, Tzouvelekis LS, Spyridopoulou K, Daikos GL. Emergence of resistance to fosfomycin used as adjunct therapy in KPC Klebsiella pneumoniae bacteraemia: report of three cases. J Antimicrob Chemother. 2012; 67:2777-2779. [PubMed: 22782489]

117. del Rio A, Gasch O, Moreno A, Pena C, Cuquet J, Soy D, et al. Efficacy and safety of fosfomycin plus imipenem as rescue therapy for complicated bacteremia and endocarditis due to methicillinresistant Staphylococcus aureus: a multicenter clinical trial. Clin Infect Dis. 2014; 59:1105-1112. [PubMed: 25048851] 


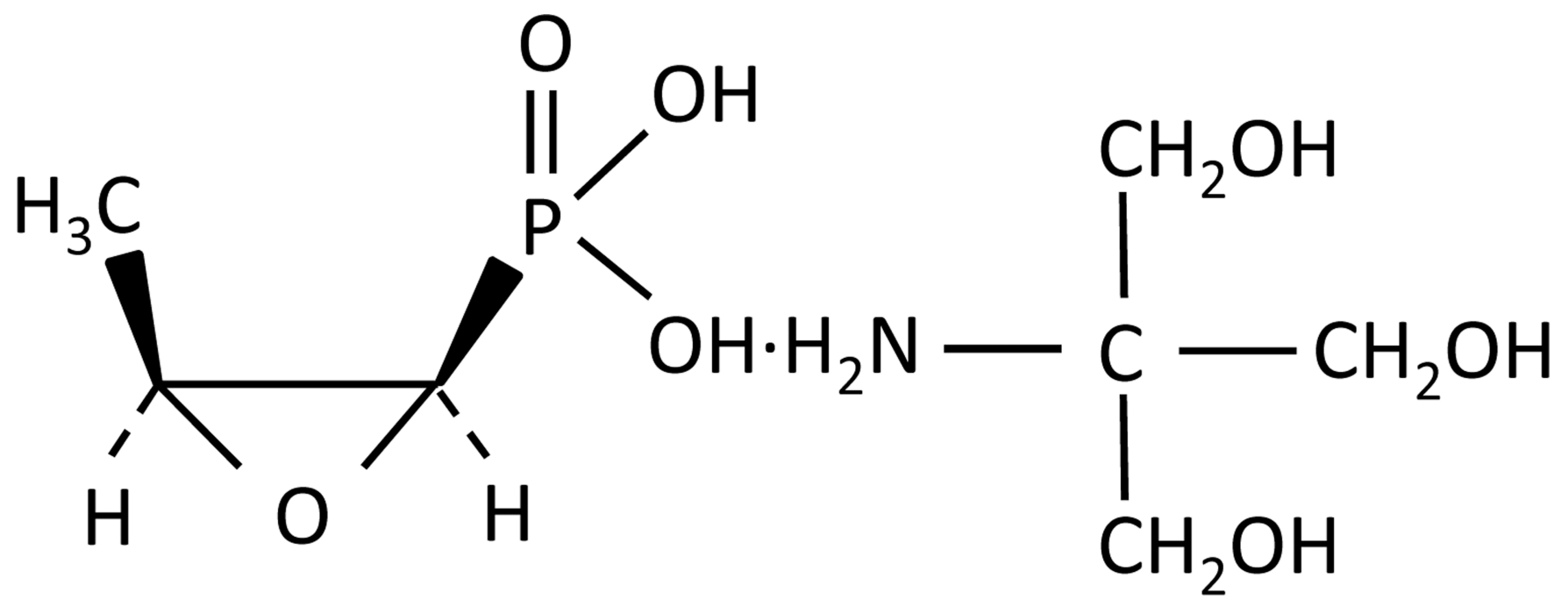

Figure 1.

Structure of fosfomycin tromethmine 


\section{Table 1}

Mechanisms of fosfomycin resistance.

\begin{tabular}{lll}
\hline Mechanism & Protein involved & Action \\
\hline Reduced permeability & GlpT & Modifications or reduced expression of glycerol-3-phosphate transporter \\
& UhpT & Modifications or reduced expression of hexose phosphate transporter \\
Target modification & MurA & Modifications or overexpression of UDP-N-acetylglucosamine 1-carboxyvinyltransferase \\
Inactivation of drug & FosA & $\mathrm{Mn}^{2+}$-dependent glutathione-S-transferase \\
& FosB & $\mathrm{Mn}^{2+} / \mathrm{Mg}^{2+}$-dependent bacillithiol-S-transferase \\
& FosX & $\mathrm{Mn}^{2+}$-dependent epoxide hydrolase \\
& FosC (FomA) & $\mathrm{Mg}^{2+} / \mathrm{ATP}-$ dependent phosphorylation of fosfomycin \\
\hline
\end{tabular}

J Infect Chemother. Author manuscript; available in PMC 2017 May 01. 


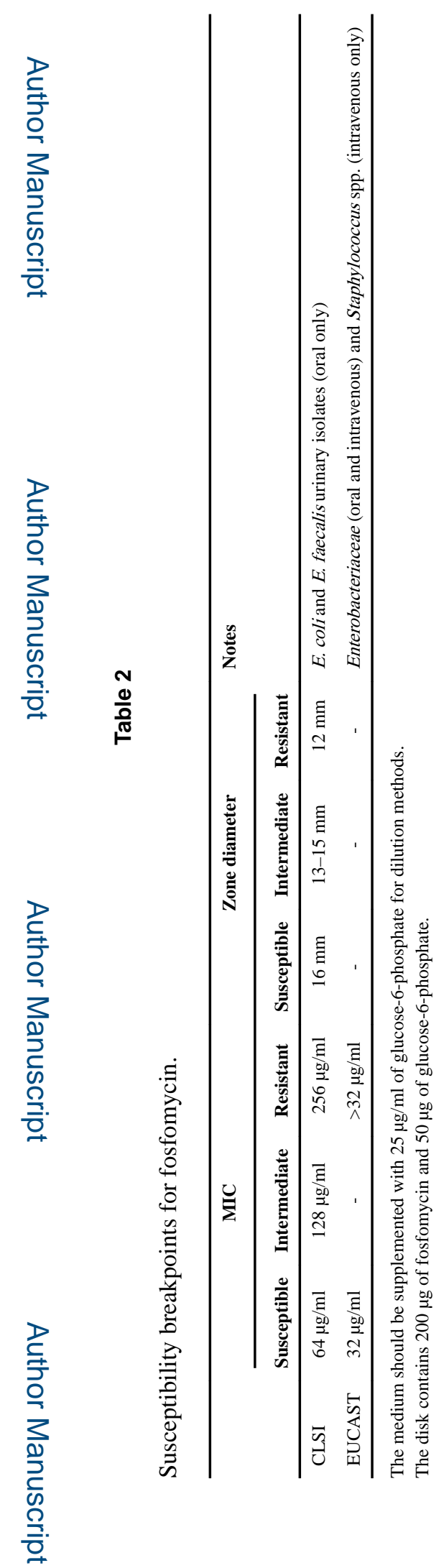

J Infect Chemother. Author manuscript; available in PMC 2017 May 01. 